(2) Open Access Full Text Article

\title{
Positive predictive value and completeness of prenatally assigned International Classification of Disease- 10 kidney anomaly diagnoses in the Danish National Patient Registry
}

\author{
This article was published in the following Dove Press journal: \\ Clinical Epidemiology \\ 18 January 2016 \\ Number of times this article has been viewed
}

\author{
Maria Rasmussen' \\ Morten Smærup Olsen ${ }^{2}$ \\ Lone Sunde ${ }^{1,3}$ \\ Lars Pedersen ${ }^{2}$ \\ Olav Bjørn Petersen ${ }^{4}$ \\ 'Department of Clinical Genetics, \\ Aarhus University Hospital, Skejby, \\ ${ }^{2}$ Department of Clinical Epidemiology, \\ Aarhus University Hospital, Skejby, \\ ${ }^{3}$ Department of Biomedicine, Aarhus \\ University, Aarhus, ${ }^{4}$ Department of \\ Gynecology and Obstetrics, Aarhus \\ University Hospital, Skejby, Denmark
}

Correspondence: Maria Rasmussen Department of Clinical Genetics, Aarhus University Hospital, Brendstrupgaardsvej 2IC, Skejby, DK-8200 Aarhus, Denmark Tel +4578455509

Fax +4586783181

Email marirasm@rm.dk
Objective: Restricting studies of severe congenital malformations to live-born children may introduce substantial bias. In this study, we estimated the attendance to the second-trimester fetal malformation screening program. We also estimated the positive predictive value (PPV) of prenatally assigned International Classification of Disease-10 diagnoses recorded in the Danish National Patient Registry (DNPR) and the completeness of case registration. We used kidney anomalies as an example.

Methods: We identified the proportion of all Danish live-born children from January 1, 2007 to December 31, 2012, who were scanned during the second trimester using the DNPR and the Civil Registration System. Details of all fetuses with specific kidney anomaly diagnoses according to the DNPR were retrieved. The PPV was estimated using the nationwide Astraia database of pregnancy medical charts or traditional medical charts, as gold standard. The completeness was assessed using the total number of cases estimated by the capture-recapture method.

Results: Of 372,263 live born infants, 97.3\% were scanned during the second trimester. We identified 172 fetuses in the DNPR. Of these, 149 had kidney anomalies according to Astraia or medical chart review, corresponding to a PPV of $87 \%$ (95\% CI: $81 \%-91 \%$ ). The estimated completeness was $43 \%$ (95\% CI: 38\%-49\%) for the DNPR and $75 \%$ (95\% CI: $70 \%-79 \%)$ for Astraia.

Conclusion: Almost all live-born children were scanned during the second trimester in Denmark. However, low completeness may hamper the use of the DNPR for studies of prenatally detected severe malformations, and use of the Astraia database may preferably be considered.

Keywords: Danish National Patient Registry, International Classification of Disease, validation study, prenatal diagnosis, Astraia, kidney anomaly, Danish Fetal Medicine Database

\section{Introduction}

The etiology of congenital malformations is heterogeneous, and in the vast majority of cases, the etiology is unknown. ${ }^{1}$ Comparing occurrence data over time may uncover unknown etiological factors, for example, newly introduced teratogens. In addition, case-control and follow-up studies of exposed and unexposed pregnancies may reveal important risk factors.

Pregnancies with a malformed fetus may be at increased risk of ending in spontaneous abortion or stillbirth, or the pregnant woman may opt for termination of pregnancy. Thus, when studying severe congenital malformations, substantial bias may be introduced if studies are restricted to live born children. ${ }^{2}$ 
Since 2006, the Danish Health and Medicines Authority has permitted fetal malformations and fetal chromosome abnormalities to be recorded in the Danish National Patient Registry (DNPR) as a diagnosis of pregnant women. The fetal diagnoses should be recorded as an additional code to a pregnancy- or abortion-related code - indicating that the diagnosis describes the fetus and not the pregnant woman. According to the guidelines, malformations in the mother should be recorded as a secondary diagnosis. ${ }^{3}$ Later in the same year, the Danish National Institute of Public Health proposed that the DNPR should serve as the basis of an improved monitoring of malformations. ${ }^{4}$

The validity and completeness of postnatally assigned malformation diagnoses in the DNPR have been investigated previously, but the positive predictive value (PPV) and completeness of prenatally assigned malformation diagnoses are unknown. ${ }^{5}$ In this study, we aimed to explore whether the DNPR can serve as a useful tool for epidemiological studies of prenatal occurrence of malformations - using cystic kidney diseases and kidney agenesia as examples. We assessed the attendance to the second-trimester malformation ultrasound screening program as the vast majority of these kidney malformations are seen at this time point, and we estimated the PPV using a combination of the nationwide Astraia database (https://www.astraia.com/en/) of electronic pregnancy medical charts and traditional medical charts as gold standards. We also assessed the completeness of the DNPR with regard to prenatally assigned malformation diagnoses.

\section{Methods}

\section{Setting}

Denmark has a national tax-funded public health care system, and all Danish citizens are registered in the Civil Personal Registry since April 1968. Each citizen has a unique tendigit civil registration number, containing the date of birth, which allows accurate matching of data sources. ${ }^{6}$ In 2004, the Danish National Board of Health published a guideline on prenatal screening, which recommended that all pregnant women must be offered, free of charge, a first-trimester risk assessment for chromosomal anomalies and a secondtrimester scan for fetal malformations. ${ }^{7}$ The full screening program was implemented at all Danish obstetric departments in June $2006 .^{8}$

\section{Data sources}

Reporting to the DNPR is mandatory and an important factor in the economic regulation of the public hospitals. ${ }^{9}$ The evaluation of prenatal diagnoses of kidney anomalies in the
DNPR was based on all malformation diagnoses issued from January 1, 2007 to December 31, 2012, as an additional code to a pregnancy- or abortion-related code.

The following specific diagnoses were included in the validation: unilateral kidney agenesia (Q600), bilateral kidney agenesia (Q601), unspecified kidney agenesia (Q602), and cystic kidney $(\mathrm{Q} 61 *)$.

Since 2006, all Danish obstetric departments use the data entry program, Astraia (Astraia Software GMBH, Munich), for recording prenatal ultrasound findings, biochemical markers, and prenatal risk assessment. Astraia essentially works as the medical chart of the pregnancy. Any prenatally detected malformation can be recorded in the Astraia database in two different ways: 1) International Classification of Disease (ICD)-10 codes can be issued; and 2) organ-specific submenus, listing all important malformations can be checked of. There has been great attention in the Danish Fetal Medicine Society regarding correct and uniform recording in Astraia, and educational sessions have been conducted at all obstetric departments.

We identified fetuses registered with kidney agenesia, cystic kidneys, multicystic kidneys, or dysplastic kidneys in Astraia. We retrieved data from all obstetric departments performing prenatal diagnostics in Denmark and merged those data into a national dataset, which included the pregnant women's unique personal identifier. If the same woman had more than one fetus in the study period meeting the inclusion criteria, only the first fetus was included in the study (four younger siblings were excluded).

If the Astraia database did not contain information on a fetus with a kidney anomaly retrieved from the DNPR, medical charts covering the pregnancy were identified and evaluated to clarify whether the fetus was misdiagnosed in the DNPR or whether the Astraia database was incomplete. During validation of the diagnoses, any diagnosis within the diagnostic group was accepted, as it is rarely possible to discriminate between different cystic kidney diseases prenatally. Furthermore, multicystic dysplastic kidneys may involute during pregnancy and appear as kidney agenesia (Figure 1).

\section{Data analysis}

To estimate the proportion of live born children scanned in the second trimester, we identified all women attending a second-trimester scan in the DNPR as well as the total number of live born children in the Civil Registration System during the study period. ${ }^{6,10}$ Twin and triplet pregnancies were counted as two and three fetuses, respectively, undergoing ultrasound examination. 


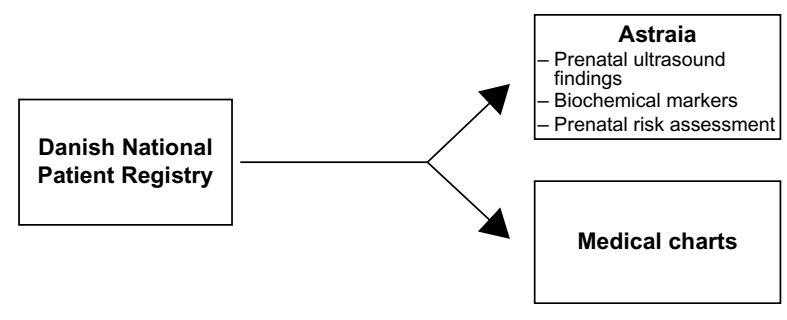

Figure I Flowchart for PPV estimation.

Notes: The PPV was estimated as the proportion of fetuses identified in the DNPR with a prenatal diagnosis of the selected kidney anomalies in whom the diagnosis could be confirmed in the Astraia database or in medical charts.

Abbreviations: DNPR, Danish National Patient Registry; PPV, positive predictive value.

The obstetric departments routinely issue a second-trimester scanning procedure code when a pregnant woman attends the second-trimester screening for fetal malformations. Procedure codes issued for 36 females younger than 14 years and four females older than 55 years were excluded from the analysis. When the code was issued twice at a woman's unique identifier $>200$ days apart, it was assumed to indicate two separate pregnancies. Similarly, codes for multiple pregnancies were assumed to indicate separate multiple pregnancies when issued $>200$ days apart.

We estimated the PPV as the proportion of fetuses identified in the DNPR with a prenatal diagnosis of the selected kidney anomalies in whom the diagnosis could be confirmed in Astraia or in medical charts (Figure 1). The completeness of the DNPR and Astraia was estimated separately as the number of fetuses registered in each data source with the specific kidney anomalies in proportion to the total number of fetuses estimated by the capturerecapture method. This method was originally developed to estimate the size of a closed animal population and has shown to be useful in estimating completeness of disease registries. The number of cases in each registry and the number common to both registries are used to estimate the total number of cases, assuming that registration in each registry is independent. ${ }^{11,12}$

We assumed that registration in the DNPR and Astraia was independent. We stratified the completeness analysis according to the calendar period as we assumed completeness would increase year by year as the new coding praxis was implemented. We also stratified the analyses of completeness according to geographical region and fetal outcome. We suspected that kidney anomalies might be recorded as less specific malformation diagnoses in the DNPR. Moreover, when the kidney anomalies coexist with other more relevant or severe malformations in the fetus, these may preferably be recorded in the DNPR. Therefore, we evaluated whether less specific definitions of the fetal malformation would increase the completeness of the DNPR.

Estimates were presented with $95 \%$ confidence intervals (CIs). For PPV and completeness estimates, the CIs were computed using Jeffery's method for binomial proportions. The CI for the estimated total number of cases was computed as described by McCarty et al. ${ }^{11}$ STATA 13 was used for statistical analyses.

The study was approved by the Danish Data Protection Agency (J no. 1-16-02-26-12). Authorization to access medical charts was obtained from the Danish Health and Medicines Authority.

\section{Results}

The total number of fetuses scanned in the second trimester in Denmark during 2007-2012 was 362,069. The total number of live births during the same period was 372,263 . Thus, the proportion of live born children scanned in the second trimester was $97.3 \%$.

We identified 172 fetuses in the DNPR diagnosed prenatally with one or more of the specific kidney anomalies. From Astraia, we retrieved 257 fetuses with equivalent diagnoses. One hundred eleven fetuses registered with kidney anomalies in the DNPR were registered with kidney anomalies in Astraia. The diagnoses that assigned the remaining 61 fetuses were validated in the medical charts. In 23 cases, medical chart review revealed that the diagnoses recorded in the DNPR did not reflect the ultrasound finding in the fetus, corresponding to an estimated PPV of $87 \%$ (95\% CI: 81\%-91\%; Table 1). In at least six of the 23 cases, the diagnosis recorded in the DNPR as a fetal diagnosis was actually the diagnosis of the pregnant woman.

Using the capture-recapture method, we estimated that the overall completeness of the DNPR was $43 \%$ (95\% CI: $38 \%-49 \%$ ) and the overall completeness of Astraia was 75\% (95\% CI: 70\%-79\%). Although most differences were insignificant, the completeness of both the DNPR

Table I PPV for the coding of selected kidney anomalies in the DNPR

\begin{tabular}{llll}
\hline & $\begin{array}{l}\text { Kidney } \\
\text { anomaly } \\
\text { in Astraia }\end{array}$ & $\begin{array}{l}\text { No kidney anomaly } \\
\text { in Astraia, but } \\
\text { kidney anomaly in } \\
\text { medical charts }\end{array}$ & $\begin{array}{l}\text { PPV\% } \\
\mathbf{( 9 5 \% ~ C l )}\end{array}$ \\
\hline $\begin{array}{l}\text { Fetuses registered } \\
\text { with kidney anomalies } \\
\text { in DNPR }(\mathrm{n}=172)\end{array}$ & $\mathrm{III}$ & 38 & 87 \\
\hline
\end{tabular}

Abbreviations: DNPR, Danish National Patient Registry; PPV, positive predictive value; $\mathrm{Cl}$, confidence interval. 
and Astraia varied with the calendar period, geographical region, and fetal outcome (Table 2). For both data sources, there was a tendency for higher completeness in the more recent calendar period and the completeness was highest in the region Funen.

By including all fetuses with any diagnosis describing malformations within the kidney or the urinary tract recorded in the DNPR, 133 out of the 257 fetuses identified with a kidney anomaly in Astraia could be retrieved from the DNPR. By including fetuses with any congenital malformation diagnoses at all, recorded in the DNPR, 143 out of the 257 fetuses from Astraia could be retrieved from the DNPR.

\section{Discussion}

We found a high PPV of fetal kidney anomaly diagnoses registered in the DNPR $(87 \%)$. In contrast, the estimated completeness of registration of fetal kidney anomaly diagnoses in the DNPR was low (43\%) compared to Astraia (75\%), and for a large proportion of fetuses with kidney anomalies according to Astraia, there was no record in the DNPR indicating any malformation at all.

Previously, postnatally assigned malformation diagnoses have been validated in the DNPR, with an overall PPV of $88 \%$ (95\% CI: 86\%-90\%) and completeness of 90\% (95\% CI: $88 \%-92 \%) .{ }^{5}$ Our study is the first study to validate prenatally assigned malformation diagnoses in the DNPR.

A PPV of $87 \%$ is acceptable for valid interpretation in many studies. However, it will affect absolute preva- lence estimates, and in the presence of nondifferential misclassification, it may lead to underestimation of the true relative effect of an exposure.

The fact that no record on kidney anomalies existed in the DNPR for more than half of stillborn fetuses or where the pregnancies were terminated is a major threat to valid absolute estimates of malformation prevalence. Furthermore, this underascertainment may bias relative risk estimates if prenatal diagnosis followed by termination of pregnancy is associated with both exposure and the malformation under study. ${ }^{2}$ Whether this type of bias is a substantial threat to the validity of a study is virtually impossible to tell.

When validating data in the English National Congenital Anomaly System, it was likewise pointed out as a major drawback that the registry did not contain data on terminated pregnancies due to prenatal diagnosis of malformations..$^{2,13}$

The low completeness of prenatally assigned malformation diagnoses in the DNPR may be a result of a lack of ICD-10 codes reflecting prenatal ultrasound findings. The ultrasound examination of the fetal kidneys may be challenged by anhydramnios and maternal obesity and it often requires a great amount of interpretation to describe an ultrasound finding using an ICD-10 code. More descriptive diagnoses reflecting the ultrasound findings are required.

Although primarily to allow more specificity of recording, the EUROCAT registry has extended the ICD-10 codes with codes from the British Paediatric Association. ${ }^{14}$ Since 1979, data from Funen regarding congenital malformations have

Table 2 Completeness of the DNPR and Astraia

\begin{tabular}{|c|c|c|c|c|c|c|}
\hline Characteristics & $\begin{array}{l}\text { Only in } \\
\text { Astraia }\end{array}$ & $\begin{array}{l}\text { Only in } \\
\text { DNPR }\end{array}$ & Both & $\begin{array}{l}\text { Estimated } \\
\text { total }(95 \% \mathrm{Cl})\end{array}$ & $\begin{array}{l}\text { Estimated } \\
\text { completeness of } \\
\text { Astraia } \%(95 \% \mathrm{CI})\end{array}$ & $\begin{array}{l}\text { Estimated } \\
\text { completeness of } \\
\text { DNPR } \%(95 \% \mathrm{CI})\end{array}$ \\
\hline Overall & 257 & 149 & III & 345 (338-352) & 75 (70-79) & $43(38-48)$ \\
\hline \multicolumn{7}{|l|}{ Year } \\
\hline 2007-2009 & 100 & 59 & 38 & I54 (I42-166) & 65 (57-72) & $38(3 \mid-46)$ \\
\hline \multirow[t]{2}{*}{$2010-2012$} & 157 & 90 & 73 & 193 (188-199) & 81 (75-86) & $47(40-54)$ \\
\hline & 257 & 149 & 111 & $348(340-355)$ & $74(69-78)$ & $43(38-48)$ \\
\hline \multicolumn{7}{|l|}{ Danish Region } \\
\hline Jutland & 129 & 84 & 67 & $162(157-166)$ & $80(73-85)$ & $52(44-59)$ \\
\hline Funen & 36 & 23 & 20 & $4 I(38-44)$ & $88(75-95)$ & $56(4 \mid-70)$ \\
\hline \multirow[t]{2}{*}{ Zealand } & 92 & 42 & 24 & $159(126-192)$ & $58(50-65)$ & $26(20-34)$ \\
\hline & 257 & 149 & 111 & $362(354-370)$ & $71(66-75)$ & $4 I(36-46)$ \\
\hline \multicolumn{7}{|l|}{ Fetal outcome } \\
\hline Live born & 183 & 99 & 77 & $235(227-243)$ & $78(72-83)$ & $42(36-49)$ \\
\hline \multirow[t]{2}{*}{ Terminated or stillborn } & 74 & 50 & 34 & $108(101-115)$ & 69 (59-77) & $46(37-56)$ \\
\hline & 257 & 149 & III & $343(335-35 I)$ & 75 (70-79) & $43(38-49)$ \\
\hline
\end{tabular}

Abbreviations: DNPR, Danish National Patient Registry; Cl, confidence interval.

Note: Estimated by the capture- recapture method. 
been reported to the EUROCAT registry. ${ }^{15}$ The slightly higher completeness in Funen may be owing to their commitment to the EUROCAT registry, which may have brought attention to the recording of malformations. ${ }^{16}$

Astraia offers some advantages over the DNPR; first, besides ICD-10 diagnoses, diagnoses can be issued in organspecific submenus. Second, simple descriptive measures, such as kidney size and "echogenic kidneys", can be recorded in predefined fields. "Echogenic kidneys" denote kidneys that appear brighter than the liver on ultrasound, but the finding is not specific for any underlying cause. ${ }^{17}$ Third, for all kidney affections, it is routinely recorded if the affection is unilateral or bilateral, which has great prognostic implications. ${ }^{18}$ Finally, diagnoses of the fetus and the pregnant woman are recorded separately.

Since January 2008, data from the local Astraia databases have been automatically transferred to the Danish Fetal Medicine Database and integrated with data imported from the DNPR, the Medical Birth Registry, and the Danish Cytogenetic Registry. ${ }^{8}$ Currently, the import of diagnoses from the local Astraia databases is extended to include the diagnoses from the organ-specific submenus, which will likely enhance data quality.

Some limitations of our study do exist. If a fetus registered in Astraia is more likely to be registered in the DNPR than a fetus not registered in Astraia or vice versa, registration in the DNPR and Astraia was not independent. This may have led us to underestimate the total number of cases by use of the capture-recapture method. ${ }^{11}$ Consequently, we may have overestimated the completeness of both data sources. Furthermore, in this study, we examined the DNPR records of selected prenatally detected kidney anomalies. These findings cannot uncritically be applied to other prenatally assigned diagnoses. However, the limitations of the ICD-10 codes and the DNPR registration procedures, where fetal malformations and fetal chromosome abnormalities are recorded as a diagnosis of the pregnant women, apply to all prenatally detected malformations.

\section{Conclusion}

Since 2007, a high proportion of live born children are scanned in the second trimester, which creates a valuable setting for the study of occurrence of severe malformations. Accurate matching of two population-based data sources made it feasible to estimate the total number of cases and highlight certain specific limitations of the DNPR data in studies of severe malformations. Astraia seems to be a superior, alternative data source for monitoring the occurrence of prenatally detected malformations. When the Danish Fetal Medicine Database is fully developed, comprehensive nationwide data from the Astraia databases will be accessible.

\section{Acknowledgments}

The work was supported by Department of Clinical Genetics, Aarhus University Hospital; Aase and Ejnar Danielsens Foundation; Helen and Ejnar Bjørnows Foundation; and Director Jacob Madsen and his wife of Olga Madsens Foundation. We would like to thank the Danish Fetal Medicine Research Group for data retrieval and data validation. The Danish Fetal Medicine Research Group: Ann Tabor: Center of Fetal Medicine, Department of Obstetrics, Copenhagen University Hospital Rigshospitalet, Copenhagen; Anne-Cathrine Shalmi: Department of Gynecology and Obstetrics, Hillerød Hospital, Hillerød; Hanne Søndergaard Jensen: Department of Gynecology and Obstetrics, Herning Hospital, Herning; Laura Vase: Department of Gynecology and Obstetrics, Viborg Hospital; Inger Stornes: Department of Gynecology and Obstetrics, Randers Hospital, Randers; Annette Hessellund: Department of Gynecology and Obstetrics, Næstved Hospital, Næstved; Lene Brendstrup: Department of Gynecology and Obstetrics, Sønderborg Hospital, Sønderborg; Olav B Petersen: Fetal Medicine Unit, Department of Obstetrics, Aarhus University Hospital, Skejby; Eske Bendsen: Department of Gynecology and Obstetrics, Esbjerg Hospital, Esbjerg; Lene Sperling: Department of Gynaecology and Obstetrics, Odense University Hospital, Odense; Steffen Sommer, Christina Kamper: Department of Gynaecology and Obstetrics, Horsens Hospital, Horsens; Helle Zingenberg: Department of Gynaecology and Obstetrics, Herlev Hospital, Herlev; Finn S Jørgensen: Fetal Medicine Unit, Department of Gynaecology and Obstetrics, Copenhagen University Hospital Hvidovre, Copenhagen; Lone Krebs, Dorte Thisted: Department of Gynaecology and Obstetrics, Holbæk Hospital, Holbæk; Lillian Skibsted: Department of Gynaecology and Obstetrics, Roskilde Hospital, Roskilde; Annette Wind Olesen: Department of Gynaecology and Obstetrics, Kolding Hospital, Kolding; Anne Sørensen: Department of Gynaecology and Obstetrics, Aalborg University Hospital, Aalborg; and Birgitte Størup: Department of Gynaecology and Obstetrics, Hjørring Hospital, Hjørring.

\section{Disclosure}

The authors report no conflicts of interest in this work. 


\section{References}

1. Dolk H, Loane M, Garne E. The prevalence of congenital anomalies in Europe. Adv Exp Med Biol. 2010;686:349-364.

2. Cragan JD, Khoury MJ. Effect of prenatal diagnosis on epidemiologic studies of birth defects. Epidemiology. 2000;11(6):695-699.

3. The Danish National Institute of Health. Common Content for Basal Registration of Hospital Patients 2006; 2005:6.

4. Helweg-Larsen K, Hermansen TS, Nybo Andersen AM. Overvågning af misdannelser og andre medfødte lidelser. Forslag til en fremtidig opdatering af misdannelsesregistreringen i Danmark. [Monitoring of malformations and other congenital diseases. Suggestions for a prospective, updated registering of malformations in Denmark]. Copenhagen: The Danish Institute of Health. 2006. Danish.

5. Larsen H, Nielsen GL, Bendsen J, Flint C, Olsen J, Sørensen HT. Predictive value and completeness of the registration of congenital abnormalities in three Danish population-based registries. Scand J Public Health. 2003;31(1):12-16.

6. Pedersen CB, Gøtzsche H, Moller JO, Mortensen PB. The Danish Civil Registration System. A cohort of eight million persons. Dan Med Bull. 2006;53(4):441-449.

7. Sundhedsstyrelsen. Retningslinjer for fosterdiagnostik - prænatal information, risikovurdering, rådgivning og diagnostic. [Guidelines regarding fetal diagnostics - prenatal information, risk assessment, counselling and diagnostics]. The Danish Institute of Health. Danish.2004.

8. Ekelund CK, Petersen OB, Jørgensen FS, et al; Danish Fetal Medicine Research Group. The Danish Fetal Medicine Database: establishment, organization and quality assessment of the first trimester screening program for trisomy 21 in Denmark 2008-2012. Acta Obstet Gynecol Scand. 2015;94(6):577-583.
9. Lynge E, Sandegaard JL, Rebolj M. The Danish National Patient Register. Scand J Public Health. 2011;39(7 Suppl):30-33.

10. Statistics Denmark. Statistics Denmark; 2015. Available from: http:// www.statistikbanken.dk. Accessed October 07, 2015.

11. McCarty DJ, Tull ES, Moy CS, Kwoh CK, LaPorte RE. Ascertainment corrected rates: applications of capture-recapture methods. Int $J$ Epidemiol. 1993;22(3):559-565.

12. Seber GF. The Estimation of Animal Abundance and Related Parameters. 2nd ed. London: Griffin and Co; 1982.

13. Boyd PA, Armstrong B, Dolk H, et al. Congenital anomaly surveillance in England - ascertainment deficiencies in the national system. BMJ. 2005;330(7481):27.

14. Boyd PA, Haeusler M, Barisic I, Loane M, Garne E, Dolk H. Paper 1: The EUROCAT network - organization and processes. Birth Defects Res A Clin Mol Teratol. 2011;91(Suppl 1):S2-S15.

15. Greenlees R, Neville A, Addor MC, et al. Paper 6: EUROCAT member registries: organization and activities. Birth Defects Res A Clin Mol Teratol. 2011;91(Suppl 1):S51-S100.

16. Winding L, Loane M, Wellesley D, et al. Prenatal diagnosis and epidemiology of multicystic kidney dysplasia in Europe. Prenat Diagn. 2014;34(11):1093-1098.

17. Hershkovitz R, Amichay K, Stein GY, Tepper R. The echogenicity of the normal fetal kidneys during different stages of pregnancy determined objectively. Arch Gynecol Obstet. 2011;284(4):807-811.

18. Al Naimi A, Baumuller JE, Spahn S, Bahlmann F. Prenatal diagnosis of multicystic dysplastic kidney disease in the second trimester screening. Prenat Diagn. 2013;33(8):726-731.
Clinical Epidemiology

\section{Publish your work in this journal}

Clinical Epidemiology is an international, peer-reviewed, open access, online journal focusing on disease and drug epidemiology, identification of risk factors and screening procedures to develop optimal preventative initiatives and programs. Specific topics include: diagnosis, prognosis, treatment, screening, prevention, risk factor modification,

\section{Dovepress}

systematic reviews, risk \& safety of medical interventions, epidemiology \& biostatistical methods, and evaluation of guidelines, translational medicine, health policies \& economic evaluations. The manuscript management system is completely online and includes a very quick and fair peer-review system, which is all easy to use. 